\title{
Ionic Migration in the Stars
}

\author{
Angel Fierros Palacios \\ Instituto de Investigaciones Eléctricas, División de Energías Alternas, Mexico City, Mexico \\ Email: afierros@iie.org.mx
}

Received 4 June 2016; accepted 27 June 216; published 30 June 2016

Copyright (@) 2016 by author and Scientific Research Publishing Inc.

This work is licensed under the Creative Commons Attribution International License (CC BY).

http://creativecommons.org/licenses/by/4.0/

(c) (i) Open Access

\section{Abstract \\ In this work, the impulsive force which is the dynamical mechanism that moves the ions inside the stars is obtained.}

\section{Keywords}

\section{Ionic Migration in the Stars}

\section{Introduction}

The ionic migration, as well as the convective streams, is two related processes that occur inside the stars. Under certain conditions, both of them produce in the Sun dynamic mechanisms that are responsible for the existence of the self-generated magnetic field, the Sunspots, and the Solar Wind. Hence, it can be assumed that those phenomena are common in all gaseous stars. So, all of them produce an intense self-generated magnetic field, Stellar Spots, and Stellar Wind. Clearly, the mechanism generator of each phenomenon is different.

\section{The Problem of the Force}

The dynamic mechanism generator of the ionic movement must be some kind of an impulsive force closely related with the thermal agent that produces the instabilities which triggers convection streams.

In order to make an appropriate analysis of the problem, it is necessary to use the momentum balance equation of magneto hydrodynamics [1]. From it, and for any gaseous star, the following equation of motion is obtained [1].

$$
\rho \frac{d \mathrm{v}}{d t}=-\operatorname{grad}\left(p+p_{r}\right)+\frac{\partial}{\partial x^{j}}\left[\sigma_{i j}^{\prime}+\frac{H_{i} H_{j}}{4 \pi}\right]
$$

where $v(x, t)$ is the velocity, $\rho(x, t)$ is the mass density, $p(x, t)$ is the whole pressure, $p_{r}(x, t)$ is the radiation pressure, and $H(x, t)$ is the self-generated magnetic field. 
The term $\sigma_{i j}(x, t)$ is the viscous part of the generalized stress tensor [2]. The viscosity is a concept defined for any continuous media. However, the phenomena considered in the theory are macroscopic; that is to say, the number of particles that form them is so big, that in any volume element it is neither possible nor desirable to distinguish individual particles. Hence, in the present problem, that viscous part can be considered as not relevant; in such a way that can be ignored for the following analysis. Thus, $v(x, t)$ is the average velocity of each sort of ions. On the other hand, it is also assumed that the mass density is only a function of the stellar radius [1]. In consequence, from (1) it follows that

$$
\frac{d}{d t}(\rho v)=-\operatorname{grad}\left[p_{g}+2 p_{r}-\frac{H^{2}}{4 \pi}\right]
$$

where [1]

$$
p=p_{g}+p_{r}
$$

and

$$
\begin{aligned}
& p_{g}=\frac{R \rho T}{\mu} \\
& p_{r}=\frac{1}{3} a T^{4} \\
& H^{2}=4 \pi p_{g}
\end{aligned}
$$

In those equations, $R$ is the gases universal constant, $T$ is the temperature, $\mu$ is the average molecular weight, and $a=7.64 \times 10^{-15}$ is the Stefan's constant [1] [3]. Then, from (2) the following final result is obtained.

$$
\frac{d}{d t}(\rho v)=-\operatorname{grad} \phi
$$

where

$$
\phi=\frac{2}{3} a T^{4}
$$

is the mechanical potential. Hence,

$$
f=-\operatorname{grad}\left(\frac{2}{3} a T^{4}\right)
$$

is the force per unit volume, which is the dynamic mechanism that move the ions, and clearly, is a function of the temperature which is the thermal agent generator of instabilities responsible of the production of convective currents.

\section{Impulse and Momentum}

From the mechanics of particles, it is well known that the change in momentum of a body acted on by an impulsive force is equal to the impulse. Thus, for any ion, it is fulfilled that

$$
d(\rho v)=f d t
$$

As the impulse is equal for both sorts of ions, from (7) the following result is obtained

$$
\rho_{H+} v_{H+}=\rho_{e-} v_{e-}
$$

So that, it has that

$$
m_{H+} v_{H+}=m_{e-} v_{e-}
$$

where the subscripts are referred to the mass and velocity of each ionic sort. Now, it seems natural to assume that the gaseous stars are formed by hydrogen. But, the mass of the ionized hydrogen is approximately equal to 2,000 times the mass of the free electron; in such a way that, from (9), it follows that 


$$
v_{e-}=2 \times 10^{3} v_{H+}
$$

In other words, the impulsive force would drag positive and negative ions in a different way; that difference depends on the mass of each type. Then, it could be expected the migration of positive ions to be slower than that of negative ions; and such a difference could make the former to reach the regions where the Sunspots are produced with a delay of 11.5 years with respect to the latter; in each Solar Cycle [1] [3]. If the big thermal fluctuation inside the stars is ignored, it is possible to make a very gross estimation of those velocities.

Let us consider that the ionized hydrogen, and also the free electrons, must travel a distance approximately equal to the Sun's radius. That is to say, the distance and the time delay that must be travel by the negative ions are

$$
\begin{aligned}
R & =6.951 \times 10^{5} \mathrm{~km} \\
t_{d} & =3.5 \times 10^{8} \mathrm{sec}
\end{aligned}
$$

If those ions move with a constant velocity, it follows that

$$
v_{H+} \approx 1.9 \times 10^{-3} \mathrm{~km} \cdot \mathrm{sec}^{-1}
$$

so that,

$$
v_{e-} \approx 3.8 \mathrm{~km} \cdot \mathrm{sec}^{-1}
$$

\section{Conclusions}

The problem of ionic migration in gaseous stars is interesting because it is the primeval cause in the creation of certain dynamical mechanisms which originate noticeable stellar phenomena whose explanation is only possible if it is assumed that inside the stars such a motion is produced.

In all gaseous stars, the ionic transits across the convective zone produce the required conditions for the creation of a dynamic mechanism which is the generator of the intense general magnetic field [1] [3]. Once the ionic migration makes its contribution to the steady-state current distribution localized in some region inside the convective zone; immediately, that ionic migration follows its path toward the stellar surface, which is again the basic process for the creation of other dynamical mechanisms that generate the Stellarspots, and the Stellar Wind. In other words, the magnetic field self-generated by all gaseous stars, the phenomenon of the Stellarspots, and the Stellar Wind, are phenomena which are generated by the ionic migration.

\section{References}

[1] Fierros Palacios, A. (2006) The Hamilton-Type Principle in Fluid Dynamics. Fundamental and Applications to Magnetohydrodynamics, Thermodynamics, and Astrophysics. Springer-Wien, New York.

[2] Fierros Palacios, A. (2015) The Sunspots. Journal of High Energy Physics, and Cosmology, 1, $72-87$.

[3] Fierros Palacios, A. (2015) The Magnetic Field in the Stability of the Stars. Journal of High Energy Physics, Gravitation and Cosmology, 1, 88-113. http://dx.doi.org/10.4236/jhepgc.2015.12008 


\section{Submit or recommend next manuscript to SCIRP and we will provide best service for you:}

Accepting pre-submission inquiries through Email, Facebook, LinkedIn, Twitter, etc.

A wide selection of journals (inclusive of 9 subjects, more than 200 journals)

Providing 24-hour high-quality service

User-friendly online submission system

Fair and swift peer-review system

Efficient typesetting and proofreading procedure

Display of the result of downloads and visits, as well as the number of cited articles

Maximum dissemination of your research work

Submit your manuscript at: http://papersubmission.scirp.org/ 